\title{
Staphylococci Surviving Intracellularly in Phagocytes from Patients Suffering from Chronic Granulomatous Disease Are Killed In Vitro by Antibiotics Encapsulated in Liposomes
}

\author{
Joachim Roesler, Stefan Hockertz, Birgit Vogt, and Marie-Luise Lohmann-Matthes \\ Fraunhofer-Institute for Toxicology, Department of Immunobiology, \\ Nikolai-Fuchs-Strasse 1, 3000 Hannover 61, Federal Republic of Germany
}

\begin{abstract}
Granulocytes and monocytes/macrophages from patients suffering from chronic granulomatous disease (CGD) are ineffective in killing specific kinds of phagocytized bacteria, e.g., Staphylococcus aureus, due to decreased or lacking ability to produce reactive oxygen intermediates. Commonly used antibiotics like flucloxacillin are of limited therapeutic value, because the staphylococci are protected against their action in the interior of phagocytes. However, encapsulation of flucloxacillin into liposomes could enable its entrance into the interior of neutrophils from two CGD patients to kill phagocytized bacteria there. The effect of rifampicin against intracellular staphylococci could be similarly enhanced by liposome encapsulation. Dose-response relations and kinetics of killing of intracellular bacteria by antibiotics in the free and encapsulated form were studied under different conditions using $\mathrm{J} 774$ mouse macrophages, because phagocytes from CGD patients are not available in great amounts. Preincubation of phagocytes with either antibiotic in liposomes subsequently endowed the cells with a strongly enhanced ability to kill phagocytized bacteria. Our data show that a drug which normally will not reach a phagosome can be delivered to this intracellular compartment by a liposome.

A possible clinical use is discussed. (J. Clin. Invest. 1991. 88:1224-1229.) Key words: chronic granulomatous disease • macrophages • liposomes $•$ Staphylococcus

Introduction

Chronic granulomatous disease (CGD) ${ }^{1}$ is characterized by severe infections with catalase positive bacteria (e.g., Staphylococcus aureus) like pyoderma, lymphadenitis with granuloma formation, abscesses in lung, liver, spleen, or bone marrow, or severe mycotic infections, etc. The clinical features of this disease are the result of a total lack of or a decreased ability of patients' phagocytes to produce microbicidal reactive oxygen
\end{abstract}

Address correspondence to Dr. Joachim Roesler, Fraunhofer-Institute for Toxicology, Department of Immunobiology, Nikolai-FuchsStrasse 1, 3000 Hannover 61, Federal Republic of Germany.

Received for publication 22 November 1989 and in revised form 11 June 1991.

1. Abbreviations used in this paper: CGD, chronic granulomatous disease; $\mathbf{M} \phi$, macrophages.

J. Clin. Invest.

(c) The American Society for Clinical Investigation, Inc.

$0021-9738 / 91 / 10 / 1224 / 06 \quad \$ 2.00$

Volume 88, October 1991, 1224-1229 intermediates. This inability is due to a variety of inherited primary biochemical disorders (1-6). Most frequently the $x-$ linked form is associated with a deficiency of nonmitochondrial cytochrome $b_{558}$ activity whereas the autosomal form is linked to a deficiency in cytosolic factor functions (7-9).

The prognosis of CGD is very poor for untreated patients, but it can be highly improved by the therapeutic and prophylactic use of antibiotics that are able to penetrate into the interior of phagocytes to kill phagocytized bacteria there. However, the number of antibiotics displaying this penetration of cell membranes is limited (10).

The liposomes of the composition used here are preferentially taken up by neutrophils, monocytes, and macrophages $(\mathrm{M} \phi)$. They are able to carry enclosed agents into the interior of these phagocytes $(11,12)$. The merits of chemotherapy of intracellular infections in phagocytes by liposome enclosed agents has been demonstrated by several investigators (13-18).

The data presented suggest that antibiotics (and perhaps antimycotics) that cannot penetrate cell membranes could perhaps become suitable for therapy of CGD by encapsulation into liposomes. Furthermore, the effectiveness of rifampicin which is already used in CGD could be enhanced by this encapsulation.

\section{Methods}

RPMI 1640 medium was supplemented with $5 \%$ pooled AB serum (both from Gibco Laboratories, Grand Island, NY, hereafter referred to as complete medium). Percoll was purchased from Pharmacia Fine Chemicals, Uppsala, Sweden, and diluted to appropriate concentrations in $\mathrm{NaCl}(0.15 \mathrm{M}$ final concentration). Distilled water and $1.8 \%$ (wt/vol) $\mathrm{NaCl}$ solution were used to lyse erythrocytes contaminating the leukocyte preparation. Liposomes were kindly provided by CibaGeigy, Basel, Switzerland. They were composed of 70\% synthetic 1-palmitoyl, 2-oleoyl-phosphatidyl-choline and 30\% synthetic 1,2-dioleoylphosphatidyl-serine. Flucloxacillin (Staphylex ${ }^{\oplus}$ ) was purchased from Beecham-Wülfing, Neuss, FRG, and rifampicin $\left(\right.$ Rimactan $\left.^{\oplus}\right)$ from Ciba-Geigy.

Preparation of liposomes containing antibiotics was performed according to the brochure of guidelines for in situ preparation from CibaGeigy. The antibiotics were dissolved in sterile isotonic Dulbecco's buffer $\mathrm{pH}=7.2$, without $\mathrm{Ca}^{2+}$ and $\mathrm{Mg}^{2+}$ salts (Ciba-Geigy) at a concentration of $250 \mathrm{mg} / \mathrm{ml}$. After sterilization by filtration, $2.5-\mathrm{ml}$ amounts of these solutions were injected through the stopper into vials containing $250 \mathrm{mg}$ lipid composed as described. After allowing the vials to stand for $15 \mathrm{~s}$ the lipid solution mixtures were then vortexed for $1 \mathrm{~min}$ at speed 7 (Vortex Genie, lab shaker model K-550-GE; lkA, Staufen, FRG). After addition of $2.5 \mathrm{ml} 0.9 \%$ (wt/vol) $\mathrm{NaCl}$ liposomes were separated from the suspension by ultracentrifugation $\left(1 \mathrm{~h}, 4^{\circ} \mathrm{C}, 50,000\right.$ g, J 2-21; Rotor JA 20/; Beckman Instruments, Inc., Palo Alto, CA).

The amounts of entrapped antibiotics were then determined. Aliquots from gently resuspended liposomes (in $0.9 \% \mathrm{NaCl}$ ) were treated by ultrasound ( $10 \mathrm{~min})$ to release the enclosed antibiotic. The resulting 
suspensions and aliquots from the supernatants resulting from the ultracentrifugation step were tested for their minimal inhibitory concentration with respect to multiplication of staphylococci. The amount of enclosed antibiotic could be calculated from the minimal inhibitory concentration of the liposome fraction and from the stock solution with known concentrations of the antibiotic under consideration. The results could be further confirmed by a balance test (calculated amounts in the liposome fractions plus calculated amounts in the supernatant were always approximately equal to the total amounts originally used). In the case of rifampicin a further confirmation could be achieved by optical density measurements at $475 \mathrm{~nm}$. The results of experiments obtained from rifampicin liposomes prepared in our lab were always identical to those obtained with rifampicin liposomes that were kindly provided by Ciba-Geigy.

Stability of the liposomes was tested according to the determination of the amounts of entrapped antibiotics. After preparation and centrifugation aliquots of the liposomal pellet were diluted 1:100 in complete medium and incubated for different time intervals at different temperatures (Fig. 1). The samples were then spun again and the contents of the respective antibiotics were evaluated in the pellet and the supernatant. Both kinds of liposomes were stable at $37^{\circ} \mathrm{C}$ over the experimental time period $(7 \mathrm{~h})$ in the medium used for cell culture (Fig. 1).

Preparation of monolayers of phagocytes. PMN were obtained by Percoll gradient centrifugation from heparinized blood $(10 \mathrm{IU} / \mathrm{ml})$. This gradient was layered in 15-ml plastic tubes (Falcon Labware, Becton Dickinson \& Co., Oxnard, CA) in two steps of 4-ml Percoll solutions: $69 \%$ (density $=1.085)$ and $55 \%($ density $=1.069)$. The tubes were spun at $350 \mathrm{~g}$ for $20 \mathrm{~min}$. PMN migrated between the two layers whereas mononuclear cells remained on the top of the gradient. The cell fractions were harvested. Remaining erythrocytes were removed by hypotonic lysis using equal volumes of distilled water and $1.8 \% \mathrm{NaCl}$ solution.

After an additional washing step in complete medium the PMN were counted and adjusted to appropriate final concentrations. After washing, the mononuclear cells were layered on a second continuous Percoll gradient according to Gmelig-Meyling (19) and centrifuged at $1,000 \mathrm{~g}$ for $25 \mathrm{~min}$. In this way dead cells, monocytes, and lymphocytes were separated into different layers. The monocyte-containing layer was harvested, the cells were washed twice and adjusted to appropriate monocyte concentrations in complete medium (the percentage of monocytes was determined by Giemsa-stained cytocentrifuge preparations).

0.2-ml amounts of the cell suspensions were incubated in flat-bottomed microtiter plates (Falcon Labware) at $37^{\circ} \mathrm{C}$, in $5 \% \mathrm{CO}_{2}$ in humidified air to allow adherence to the plastic (PMN: $1 \mathrm{~h}$; monocytes: overnight). After gentle washing to remove nonadherent cells, the phagocytes were incubated with staphylococci or liposomes under the same conditions, detailed in the figure legends.

CGD phagocytes were isolated from blood samples of two CGD patients. These cells were cytochrome $b_{558}$ negative as determined by staining with the monoclonal antibody 7D5 (a kind gift from M. Nakamura, Cell Chemistry, Institute of Medical Science, Tokyo, Japan) and subsequent flow microcytofluorometry (FACScan ${ }^{\bullet}$, Becton Dickinson $\&$ Co.). Consequently, no reactive oxygen intermediates at all were produced by these cells after stimulation with phorbol myristate acetate as determined by lucigenine-dependent chemiluminescence and cytochrome c-reduction. Four blood samples were taken at different time points from patient I and one blood sample from patient II. Cells from both patients were used for the experiments represented by Fig. 1 .

Staphylococcus aureus strain 502 A (ATCC 27217; American Type Culture Collection, Rockville, MD [20]) was cultured by growth in trypticase soya broth (Oxoid Ltd., Basingstoke, England). 2-ml samples were stored at $-70^{\circ} \mathrm{C}$, diluted appropriately, and adapted to $37^{\circ} \mathrm{C} 30$ min before use. Plate counting was performed according to standard techniques on trypticase soya agar (Oxoid).

J 774 A.1, a mouse monocyte-macrophage cell line, had been adapted to culture from a tumor which arose in a female BALB/c mouse in 1968 (ATCC TIB 67). It was maintained as a tissue culture in RPMI 1640 medium supplemented with $10 \%$ calf serum and $0.1 \%$ gentamicin. All components were purchased from Gibco Laboratories. In our lab, the $\mathbf{J} 774$ cells were found to display good phagocytosis of staphylococci, but their ability to kill the bacteria spontaneously was limited. Therefore, these cells were found to be suitable for complementary experiments, because CGD phagocytes were not available in sufficient amounts.

Statistical analysis. Great variability of CFU numbers hampers any reasonable averaging of different experiments. Therefore, representative results are given in Figs. 2, 3, and 4 (of three experiments for each condition in Figs. 3 and 4). All measurements were done in triplicate and standard deviations are given in Fig. 2. They have been omitted in Figs. 3 and 4 for clarity, the maximal deviation being $25 \%$ of the mean. The range of scatter and the results of the Wilcoxon-Rank test of four series of experiments are given in Table I to ensure the statistical significance of the results.

\section{Results}

Encapsulation of flucloxacillin into the liposomes ranged from 50 to $90 \%$ of the total amount used as determined by a microbicidal assay (see Methods).
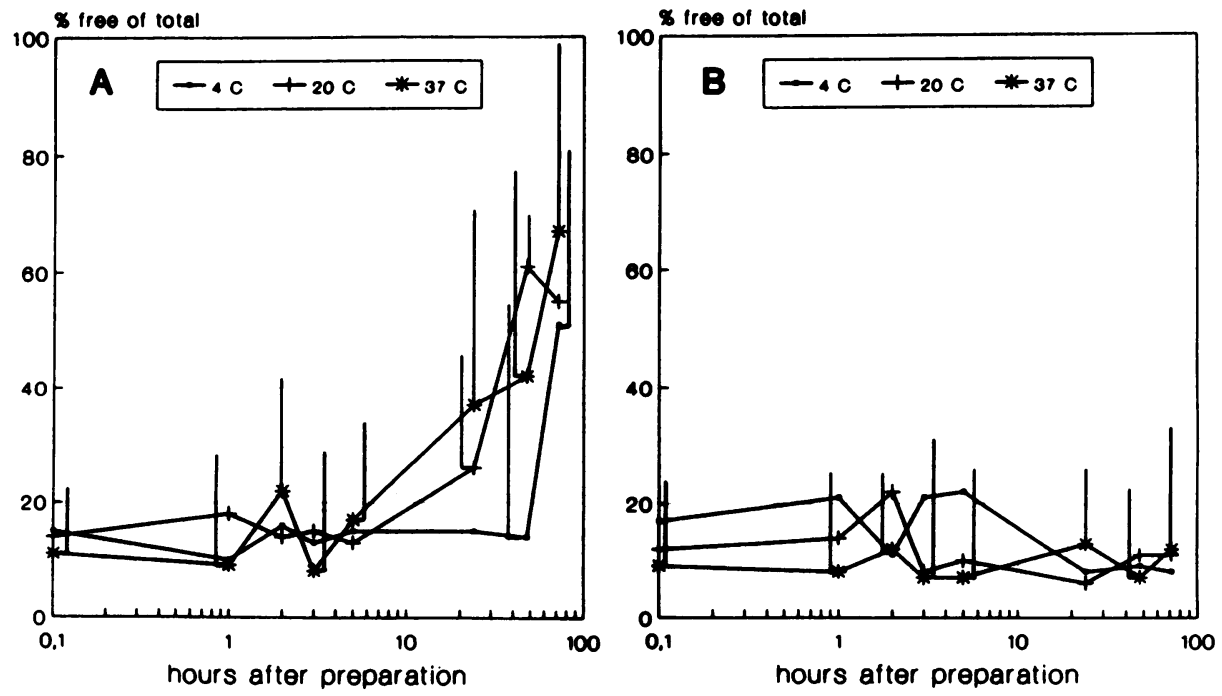

Figure 1. Stability of liposomes containing the antibiotics at different temperatures. $(A)$ flucloxacillin; $(B)$ rifampicin. After different time intervals, the content of the respective antibiotic in the medium (supernatant) was calculated as percent of the total. Medians and maximal values (top of the error bars) are given, $n=5$. Error bars for $4^{\circ} \mathrm{C}$ and $20^{\circ} \mathrm{C}$ were in part omitted for clarity. 

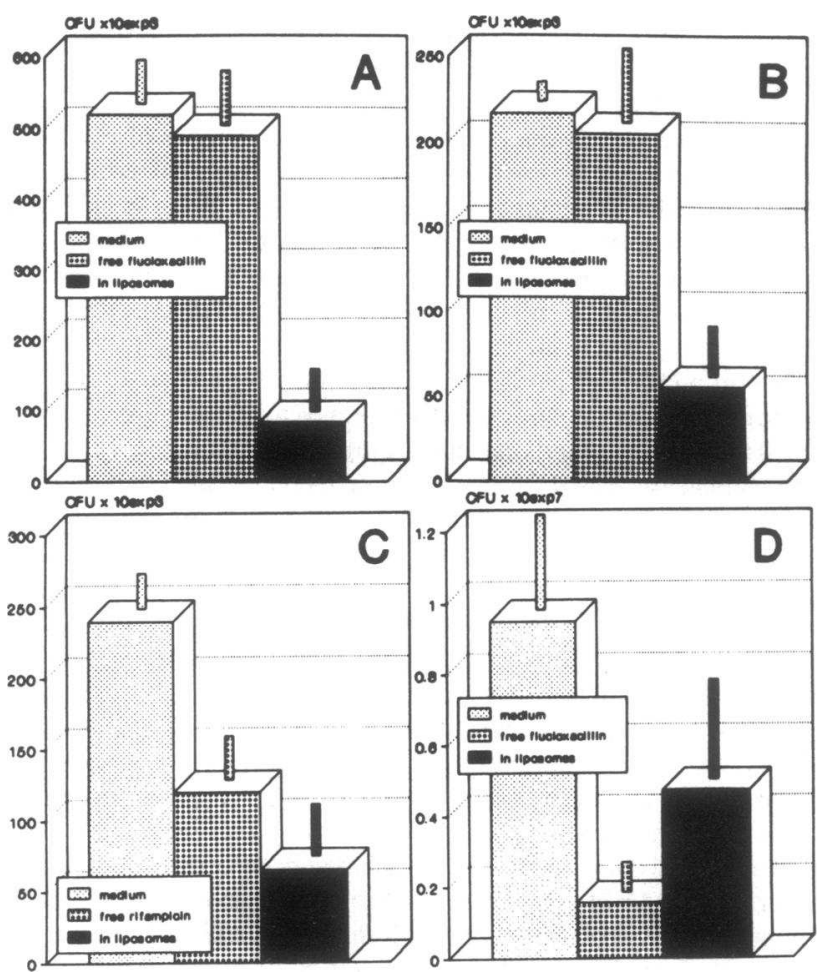

Figure 2. Killing of staphylococci surviving intracellularly in phagocytes from a CGD patient by flucloxacillin in liposomes. $5 \times 10^{5}$ adherent $\operatorname{PMN}(A)$ or $2 \times 10^{5}$ monocytes $(B)$ were preincubated with the bacteria $(E: T=1: 5)$ for $1 \mathrm{~h}$ to enable phagocytosis. After removal of extracellular bacteria by washing twice, the cells were incubated for $2 \mathrm{~h}$ with flucloxacillin $(A: 1 \mu \mathrm{g} / \mathrm{ml} ; B: 0.5 \mu \mathrm{g} / \mathrm{ml})$ or rifampicin $(C$ : $10 \mathrm{ng} / \mathrm{ml}$ ). After an additional washing step, resulting CFU were calculated after hypotonic lysis of the cells by plate counting. $(D)$ Free bacteria (without cells) were incubated for $2 \mathrm{~h}$ with free vs. encapsulated flucloxacillin $(1 \mu \mathrm{g} / \mathrm{ml})$ simultaneously to and under the same test conditions as in $A$. A representative result of five $(A, D)$ or three $(B, C)$ experiments is given.

\section{Effects on staphylococci in CGD neutrophils}

The ability of this liposome-encapsulated flucloacillin to kill intracellular bacteria was tested as follows: PMN lacking any ability to produce reactive oxygen intermediates from CGD patients were incubated with staphylococci to enable phagocytosis of these bacteria. After removal of most remaining extracellular bacteria by washing, the PMN were incubated with flucloxacillin either enclosed in liposomes or in the free form. Plate counting revealed that a significant reduction of viable bacteria was achieved by liposome-encapsulated flucloxacillin only (Fig. $2 \mathrm{~A}$ ): the number of bacteria surviving intracellularly was $\sim 20 \%$ of the respective number resulting from incubation with free flucloxacillin or with medium only. Similar results were obtained using monocytes instead of PMN (Fig. 2 B).

Similar experiments were performed using $10 \mathrm{mg} / \mathrm{ml} \mathrm{ri-}$ fampicin instead of flucloxacillin. The killing of intracellular staphylococci in CGD PMN was enhanced significantly by encapsulation of rifampicin into liposomes, but the amount of improvement over the free form was less than that of flucloxacillin (it was $\sim 40 \%$, Fig. $2 C$, vs. $80 \%$, Fig. $2 A$ ). This smaller encapsulation effect is probably due to the fact that free rifampicin can penetrate membranes of cells while flucloxacillin can not.
As a control, free staphylococci were incubated with free vs. enclosed antibiotics (Fig. 1 D). As expected, free antibiotics were always significantly more effective in reducing the number of extracellular bacteria. In addition, empty liposomes in concentrations used here had no effect on survival or on multiplication of free or phagocytized staphylococci (Fig. 5). Furthermore, the presence of empty liposomes neither decreased the number of phagocytized bacteria nor enhanced the weak spontaneous killing in $\mathbf{J} 774$ mouse macrophages by activation.

\section{Dose response relations and kinetics of killing of staphylococci in $\mathrm{J} 774$ phagocytes}

These cells were used for more detailed studies of dose response relations and kinetics of bacterial killing because cells from CGD patients are not available in great amounts. The better effect of antibiotics in liposomes on the killing of phagocytized bacteria over a wide range of concentrations is demonstrated in Fig. 3, $A$ and $C$. Especially, the minimal inhibitory concentrations were decreased and low concentrations became more effective by encapsulation. This could be confirmed by the ki-
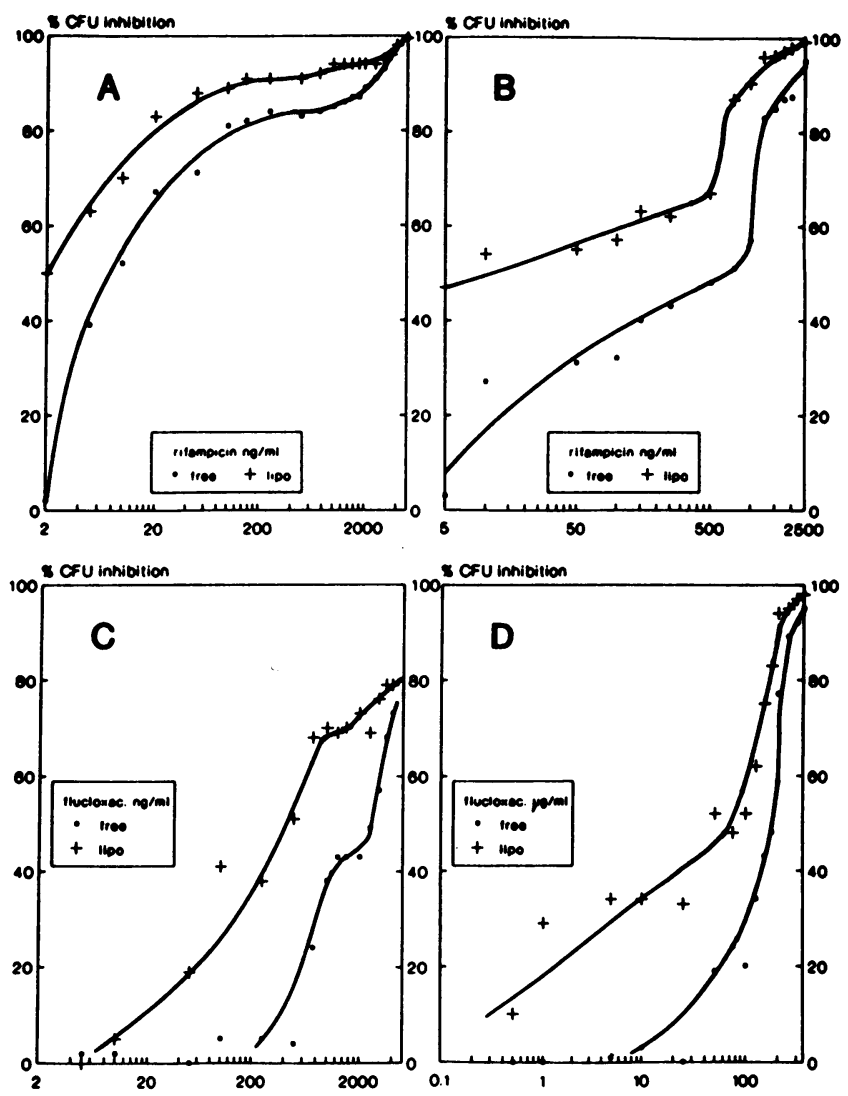

Figure 3. Dose response relations of growth inhibition and killing of intracellular staphylococci by free and encapsulated (lipo) antibiotics. $2 \times 10^{5}$ adherent J $774 \mathrm{M} \phi$ were preincubated with $2 \times 10^{6}$ staphylococci for $1 \mathrm{~h}$ to enable phagocytosis, washed twice, and incubated with the respective antibiotic for $5 \mathrm{~h}$. A, C, or the $\mathrm{J} 774 \mathrm{M} \phi$ were preincubated with the respective antibiotic $B, D$ for $1 \mathrm{~h}$, washed twice, further incubated with the bacteria for $1 \mathrm{~h}$, washed twice again, and then incubated in medium for $5 \mathrm{~h}$. After another washing step, resulting CFU were calculated after hypotonic lysis of the cells by plate counting. These CFU numbers were compared to those resulting from incubation without antibiotic and the percentages of inhibition were calculated. 

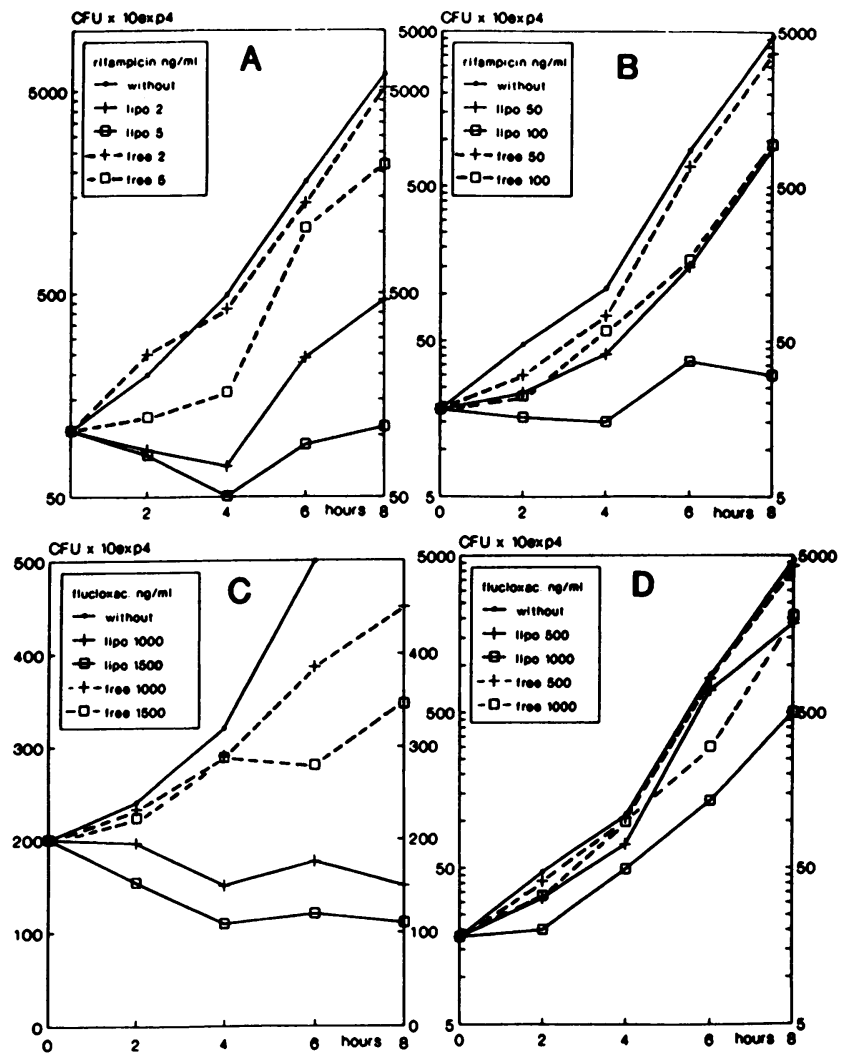

Figure 4. Kinetics of growth inhibition and killing of intracellular staphylococci by free and encapsulated (lipo) antibiotics. $A, C$ : preincubation of $\mathrm{J} 774 \mathrm{M} \phi$ with bacteria and addition of the antibiotics afterwards. $B, D$ : preincubation of $\mathrm{J} 774 \mathrm{M} \phi$ with the antibiotics, phagocytosis of bacteria afterwards, and following incubation in medium. Some test conditions including washing stages as in Fig. 2.

netics of killing of intracellular bacteria (Fig. 4, $A$ and $C$ ). Rifampicin $(A)$ and flucloxacillin $(C)$ in concentrations which in the free form still allow multiplication of the staphylococci became more bacteriostatic or even bactericidal by encapsulation. The J 774 macrophages could be endowed with strongly enhanced abilities to kill staphylococci by preincubation with relatively low concentrations of encapsulated antibiotics (Fig.
3, $B$ and $D$ ). Much higher concentrations of the free forms were needed for similar effects. Again, this result could be confirmed by kinetic studies (Fig. 4, $B$ and $D$ ).

In contrast to free rifampicin, preincubation of $\mathrm{J} 774$ cells with $100 \mathrm{ng} / \mathrm{ml}$ of the encapsulated form had a bacteriostatic effect (Fig. 4 B). However, preincubation with $1 \mu \mathrm{g} / \mathrm{ml}$ flucloxacillin in liposomes could only decrease but could not stop bacterial multiplication $(D)$.

Two similar experiments preincubating phagocytes with antibiotics could be carried out with neutrophils from a CGD patient. CFU numbers resulting from 2-h preincubation with $0.1 \mathrm{mg} / \mathrm{ml}$ rifampicin or $1 \mathrm{mg} / \mathrm{ml}$ flucloxacillin in liposomes were $\sim 50 \%$ or $40 \%$, respectively, as compared to preincubation with the free form. Thus, the results using $\mathrm{J} 774$ macrophages are transferable in principle to CGD phagocytes.

To further exclude the possibility that these results were due to disturbance of phagocytosis caused by liposomes or antibiotics, we incubated pretreated $\mathrm{J} 774$ cells with yeast cells of the species Candida albicans. Phagocytosis of this yeast was not altered by any of the pretreatments used as determined by cell staining according to Pappenheim and microscopical counting of 200 cells for each condition.

To test whether liposomes suppress intracellular bacterial growth by delivery of antibiotics or by providing an adjuvant effect, we incubated cells containing bacteria with free antibiotics and empty liposomes (Fig. 5). Since only encapsulation of antibiotics, but not addition of empty liposomes, increased killing of intracellular bacteria, we conclude that liposomes do not provide an adjuvant effect. The statistical significance and the range of scatter of the results for all test conditions are given in Table I.

\section{Discussion}

PMN from CGD patients show normal phagocytosis of staphylococci, but are ineffective in killing them. Flucloxacillin is not able to penetrate cell membranes of PMN or monocytes. Therefore, its therapeutic effect in CGD is very limited because common pathogenic bacteria like Staphylococcus aureus are protected intracellularly against its action. Liposomes could enable entrance of the antibiotic into the interior of phagocytes from two CGD patients to kill phagocytized staphylococci

Table I. Intracellular Killing by Liposomal Encapsulated Antibiotics

\begin{tabular}{|c|c|c|c|c|c|c|c|}
\hline \multicolumn{3}{|c|}{ Incubation periods of $2 \times 10^{5}$ adherent $\mathrm{J} 774$ cells per well } & \multicolumn{5}{|c|}{ Ratio (CFU free AB) vs. (CFU Lipo-AB) } \\
\hline $1 \mathrm{~h}$ & $1 \mathrm{~h}$ & $5 \mathrm{~h}$ & Minimum & Maximum & Median & $n$ & $P<$ \\
\hline $\begin{array}{c}\text { Flucloxacillin } \\
1.5 \mu \mathrm{g} / \mathrm{ml}\end{array}$ & $\begin{array}{l}\text { Staphylococcus aureus } \\
\qquad 2 \times 10^{6}\end{array}$ & Medium & 1.6 & 4.2 & 2.4 & 6 & 0.02 \\
\hline- & $\begin{array}{l}\text { S. aureus } \\
2 \times 10^{6}\end{array}$ & $\begin{array}{c}\text { Flucloxacillin } \\
1.5 \mu \mathrm{g} / \mathrm{ml}\end{array}$ & 1.5 & 3.8 & 2.2 & 7 & 0.008 \\
\hline $\begin{array}{c}\text { Rifampicin } \\
1 \mu \mathrm{g} / \mathrm{ml}\end{array}$ & $\begin{array}{l}\text { S. aureus } \\
2 \times 10^{6}\end{array}$ & Medium & 3.1 & 14 & 5.3 & 6 & 0.02 \\
\hline- & $\begin{array}{l}\text { S. aureus } \\
2 \times 10^{6}\end{array}$ & $\begin{array}{c}\text { Rifampicin } \\
1 \mu \mathrm{g} / \mathrm{ml}\end{array}$ & 1.8 & 3.9 & 2.6 & 5 & 0.035 \\
\hline
\end{tabular}

Statistical significance of the enhancement of intracellular killing by liposome encapsulation of antibiotics for the different test conditions. Two washing stages were included between all incubation periods. (CFU free AB), (CFU Lipo AB): CFU numbers resulting from incubation with the free or the liposome-encapsulated antibiotic, respectively. 


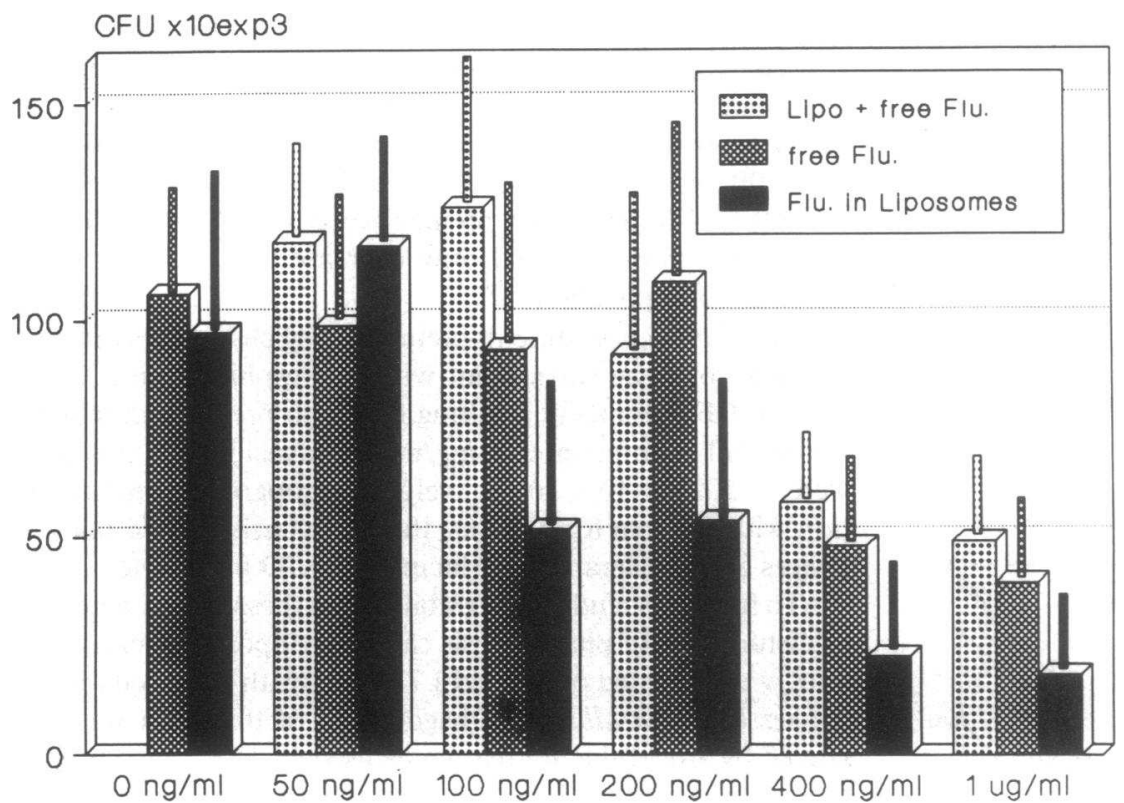

Figure 5. Growth inhibition and killing of intracellular staphylococci is not influenced by empty liposomes. Same test conditions as in Fig. $3 C$. Lipo: empty liposomes; Flu.: flucloxacillin; abscissa: concentration of flucloxacillin. Left hatched bar $(0 \mathrm{ng} / \mathrm{ml})$ : intracellular number of CFU after incubation in medium only; left black bar $(0 \mathrm{ng} / \mathrm{ml})$ : intracellular number of CFU after incubation with empty liposomes in the same concentration as used for enclosure of $500 \mu \mathrm{g} / \mathrm{ml}$ flucloxacillin in Fig. 3, $C$ and $D$. Empty liposomes (dotted bars) were used in the same concentrations as the respective liposomes containing flucloxacillin for all concentrations of this antibiotic. Five measurements for each condition. there (Fig. 2). Furthermore, encapsulation of rifampicin (which can penetrate cell membranes) into liposomes could significantly enhance its effect against intracellular bacteria (Fig. $3 \mathrm{~A}$; $4 A$ ). This could be the result of enrichment of this antibiotic intracellularly.

When J $774 \mathrm{M} \phi$ were preincubated with antibiotics (flucloxacillin or rifampicin) encapsulated into liposomes, the cells were endowed with enhanced ability to kill staphylococci (Fig. $3, B$ and $D ; 4, B$ and $D$ ). Obviously, after preincubation effective bactericidal concentrations were still present in the interior of the cells, although the antibiotics had been removed from the extracellular medium.

Our data show that a drug which normally will not (or will only in a low concentration) reach a phagosome can be delivered to this intracellular compartment by a liposome. Therefore, in CGD the effectiveness of antibiotics like flucloxacillin, previously of limited therapeutic value, could perhaps be enhanced by encapsulation into liposomes.

This view is further supported by results obtained from animal models. Bacteria surviving intracellularly in phagocytes of mice in vivo could be eliminated much more efficiently by treatment of the animals with liposome-enclosed antibiotics than by treatment with free antibiotics (e.g., 21; see also Introduction).

Liposomes of the composition used here are preferentially taken up by $\mathbf{M} \phi$ in liver and spleen (and to some extent by those in bone marrow) after i.v. application (22). The same $\mathbf{M} \phi$ phagocytize bacteria which were delivered into the blood stream. Therefore, $\mathbf{M} \phi$ of CGD patients could eventually be endowed with the ability to kill bacteria by liposome-encapsulated antibiotics (flucloxacillin, rifampicin, or others) avoiding the most common abscesses in the liver.

Studies on liposome-macrophage interactions have shown that the majority of liposomes that became cell associated are rapidly internalized by the cells (23-25). However, the extent of liposome binding and subsequent ingestion by macrophages' phagosomes is greatly influenced by the type of liposomes employed. Especially, multilamellar vesicles as used here are better internalized than small unilamellar vesicles of identical lipid composition (26). Liposomes containing negatively charged phospholipids are better bound to and phagocytized by macrophages.

In addition, ultrastructural studies (27) on the uptake of liposomes by liver macrophages infected with Leishmania donovani have indicated that internalized liposomes probably fuse with the phagosome (here the parasitophorous vacuole), transferring their contents into the immediate locality of the infectious organisms. This study suggests that this is the way in which liposome-entrapped agents have an enhanced therapeutic effect over free drug therapy.

However, before a clinical protocol can be scheduled, some issues should be clarified which cannot be discussed here in detail: ( $a$ ) stability of the liposomes in vivo; $(b)$ risk of sensitization of the patient against substances enclosed in liposomes; $(c)$ altered pharmacokinetics; and $(d)$ altered toxicity of the enclosed agent. Experience with amphotericin B demonstrates that enhancement of toxicity by encapsulation into liposomes is unlikely $(13,18)$.

\section{References}

1. Cooper, M. R., L. R. DeChatelet, C. E. McCall, M. F. LaVia, C. L. Spurr, and R. L. Baehner. 1972. Complete deficiency of leukocyte glucose-6-phosphate dehydrogenase with defective bactericidal activity. J. Clin. Invest. 51:769-778.

2. Giblett, E. R., S. J. Klebanoff, S. H. Pincus, J. Swanson, B. H. Park, and J. McCullough. 1971. Cell phenotypes in chronic granulomatous disease: a potential transfusion hazard. Lancet. i:1235-1236.

3. Harvath, L., and B. R. Andersen. 1979. Defective initiation of oxidative metabolism in polymorphonuclear leukocytes. N. Engl. J. Med. 300:1130-1135.

4. Segal, A. W., O. T. G. Jones, D. Webster, and A. C. Allison. 1978. Absence of a newly described cytochrome b from neutrophils of patients with chronic granulomatous disease. Lancet. ii:446-449.

5. Weening, R. S., D. Roos, C. M. R. Weemaes, J. W. T. Homan-Müller, and M. L. J. van Schaik. 1976. Defective initiation of the metabolic stimulation in phagocytizing granulocytes: a new congenital defect. J. Lab. Clin. Med. 88:757768.

6. Whitin, J. C., C. E. Chapman, E. R. Simons, M. E. Chovaniec, and H. J. Cohen. 1980. Correlation between membrane potential changes and superoxide production in human granulocytes stimulated by phorbol myristate acetate. Evidence for defective activation in chronic granulomatous disease. J. Biol. Chem. 255:1874-1878.

7. Caldwell, S. E. C. E. McCall, C. L. Hendricks, P. A. Leone, D. A. Bass, and L. C. McPhail. 1988. Coregulation of NADPH oxidase activation and phosphor- 
ylation of a 48-kD protein(s) by a cytosolic factor defective in autosomal recessive chronic granulomatous disease. J. Clin. Invest. 81:1485-1496.

8. Nunoi, H., D. Rotrosen, J. I. Gallin, and H. L. Malech. 1988. Two forms of autosomal chronic granulomatous disease lack distinct neutrophil cytosol factors. Science (Wash. DC). 242:1298-1301.

9. Volpp, D. B., W. M. Nauseff, and R. A. Clark. 1988. Two cytosolic neutrophil oxidase components absent in autosomal chronic granulomatous disease. Science (Wash. DC). 242:1295-1297.

10. Höger, P. H., R. A. Seger, and W. H. Hitzig. 1984. Chronic granulomatous disease: correction of the bactericidal defect by intracellularly active antibiotics. In Progress in Immunodeficiency Research and Therapy. C. Griscelli and J. Vossen, editors. Elsevier Science Publishers B.V., Amsterdam, New York. 173-174.

11. Poste, G. 1983. Liposome targeting in vivo: problems and opportunities. Biol. Cell. 47:19-30.

12. Poste, G., R. Kirsh, and T. Koestler. 1983. The challenge of liposome targeting in vivo. In Liposome Technology. G. Gregoriadis, editor. CRC Press, Boca Raton, FL. 1-28.

13. Lopez-Berestein, G., R. Mehta, R. L. Hopfer, K. Mills, L. Kasi, K. Mehta, V. Fainstein, M. Luna, E. M. Hersh, and R. Juliano. 1983. Treatment and prophylaxis of disseminated infection due to Candida albicans in mice with liposome-encapsulated amphotericin B. J. Infect. Dis. 147:939-945.

14. Graybill, J. R., P. C. Craven, R. L. Taylor, D. M. Williams, and W. E. Magee. 1982. Treatment of murine cryptococcosis with liposome associated amphotericin B. J. Infect. Dis. 145:748-751.

15. Fountain, M. W., C. Dees, and R. D. Schultz. 1981. Enhanced intracellular killing of Staphylococcus aureus by canine monocytes treated with liposome containing amikacin, gentamicin, kanamycin, and tobramycin. Curr. Microbiol. 6:373-376.

16. Alving, C. R., and E. A. Steck. 1979. The use of liposome-encapsulated drugs in leishmaniasis. Trends Biochem. Sci. 4:N175-177.

17. Desiderio, J. V., and S. G. Campbell. 1983. Liposome-encapsulated cephalothin in the treatment of experimental murine salmonellosis. RES J. Reticuloendothel. Soc. 34:279-287.
18. Juliano, R. L., G. Lopez-Berenstein, R. Mehta, R. Hopfer, K. Mehta, and L. Kasi. Pharmacokinetic and therapeutic consequences of liposomal drug delivery: fluorodeoxyuridine and amphotericin B as examples. Biol. Cell. 47:39-46.

19. Gmelig-Meyling, F., and T. A. Waldmann. 1980. Separation of human blood monocytes and lymphocytes on a continuous Percoll gradient. J. Immunol. Methods. 33:1-9.

20. Shinefield, H. R., and J. C. Ribble. 1963. Bacterial interference: its effect on nursery acquired infection with Staphylococcus aureus. Am. J. Dis. Child. 105:646-691.

21. Bakker-Woudenberg, I. A. J. M., A. F. Lokerse, F. H. Roerdink, D. Regts, and M. F. Michel. 1985. Free versus liposome-entrapped ampicillin in treatment of infection due to Listeria monocytogenes in normal and athymic (nude) mice. $J$. Infect. Dis. 151:917-924.

22. Hockertz, S., G. Franke, E. Kniep, and M. L. Lohmann-Matthes. 1989. Mouse interferon- $\gamma$ in liposomes: pharmacokinetics, organ-distribution, and activation of spleen and liver macrophages in vivo. J. Interferon Res. 9:591-602.

23. Poste, G., R. Kirsh, W. E. Fogler, and I. J. Fidler. 1979. Activation of tumoricidal properties in mouse macrophages by lymphokines encapsulated in liposomes. Cancer Res. 39:881-892.

24. Gregoriadis, G., and R. A. Buckland. 1973. Enzyme containing liposomes alleviate a model for storage disease. Nature (Lond.). 244:170-172.

25. Weissmann, G., D. Bloomgarden, R. Kaplan, C. Cohen, S. Hoffstein, T. Collins, A. Gotlkieb, and D. Nagle. 1975. A general method for the introduction of missing enzymes into the cytoplasm of cultured mammalian cells by means of immunoglobulin-coated liposomes, into lysosomes of deficient cells. Proc. Natl. Acad. Sci. USA 72:88-92.

26. Schroit, A. J., and I. J. Fidler. 1982. Effects of liposome structure and lipid composition on the activation of the tumoricidal properties of macrophages by liposomes containing muramyl dipeptide. Cancer Res. 42:161-167.

27. Heath, S., M. L. Chance, and R. R. C. New. 1984. Quantitative and ultrastructural studies on the uptake of drug loaded liposomes by mononuclear phagocytes infected with Leishmania donovani. Mol. Biochem. Parasitol. 12:4960 . 